\title{
Interleukin-4 gene intron 3 VNTR polymorphism in adult acute myeloid leukemia
}

\author{
Nesma A. Safwat ${ }^{1}$, Marwa R. El Najjar ${ }^{1}$, Alia M. Saeed ${ }^{2}$ and Haydi S. Mohamed ${ }^{2 *}$
}

\begin{abstract}
Background: The proliferation of acute myeloid leukemia (AML) blast into the bone marrow microenvironment is controlled by cytokines. Interleukin-4 (IL-4) has recently been discovered to suppress the development and persistence of AML cells selectively. Intron three of the Interleukin-4 (IL-4) gene contains a 70-bp minisatellite region polymorphism that may influence gene transcriptional activity and subsequently affect the production level of IL4. We investigated the IL-4 gene intron three variable number tandem repeat (VNTR) polymorphism as a molecular marker in AML associated with clinical and laboratory variables and a prognostic factor for therapeutic response and disease outcome.

Results: IL-4 gene intron three minisatellite regions polymorphism was assessed in 60 adult AML patients and 60 healthy controls, comparable concerning age and gender, using polymerase chain reaction. Three study marker genotypes were detected in AML patients; P1/P1 (3\%), P1/P2 (40\%), and P2/P2 (56.7\%). The frequency of P2 alleles was significantly more in AML patients than in healthy controls (76.7\% versus $25 \% ; P<0.001)$. Compared to the heterozygous group and P1/P1 carriers, AML patients with the homozygous P2/P2 genotype had a higher total leucocytic count and increased blast percentages in bone marrow or peripheral blood, besides a lower platelet count. P2P2 genotype was also significantly associated with poor therapeutic response, higher susceptibility to disease recurrence and shorter overall survival and disease-free survival.

Conclusion: The IL-4 intron 3 VNTR polymorphism could be included in the molecular risk stratification of AML to predict poor disease. This information can be utilized in incorporating biological therapy into the present therapeutic protocols to enhance chemotherapy regimens' current low response rates.
\end{abstract}

Keywords: AML, IL4, VNTR

\section{Background}

Several molecular and cytogenic abnormalities characterize acute myeloid leukemia (AML). Since cytokines and growth factors are generated in the medullary microenvironment, and they regulate cell survival, proliferation, and differentiation, polymorphisms in their respective genes may influence cancer susceptibility [1].

\footnotetext{
*Correspondence: haydisayed@hotmail.com

${ }^{2}$ Clinical Hematology and Bone Marrow Transplantation Unit,

Department of Internal Medicine, Faculty of Medicine, Ain Shams

University, Cairo, Egypt

Full list of author information is available at the end of the article
}

Interleukin 4 (IL4) is a well-known T-helper 2 (Th2) cytokine. It is a pleiotropic cytokine that has a dichotomous role in inducing cancer. According to some studies, IL-4 prevents carcinogenesis by promoting apoptosis. In contrast, other researchers disagree with this theory, claiming that IL-4 enhances tumor growth, spread, and metastasis [2].

The IL4 gene is located in the cytokine cluster region on the long arm of chromosome 5 (5q31-33), with four exons and three introns. Polymorphisms affecting the intron-3 minisatellite 70 bp region may influence its transcriptional activity, resulting in three-repeat allele, tworepeat allele, or the rare four-repeat allele [3]. 
Even though an increasing number of studies have been designed to investigate how IL4-intron 3 VNTR polymorphism can influence human cancer risk, only one study has examined the association between the IL-4 intron-3 VNTR polymorphism and different types of leukemias [4].

In the present study, we evaluated the different genotypes of IL4- intron 3 VNTR polymorphism in Egyptian adult AML patients and investigated its association with clinical and laboratory data, chemotherapy response, and disease outlook.

\section{Methods}

\section{Patients selection}

This prospective study was conducted on 60 newly diagnosed adults with AML recruited from the Hematology Unit of Ain Shams University hospital during the years 2018-2019 and 60 healthy controls of age and sex-matched.

\section{- Inclusion criteria}

Newly diagnosed AML patients aged 16-60 years who are candidates for induction chemotherapy

- Exclusion criteria

Relapsed and resistant AML cases were excluded Patients not fit for chemotherapy or on palliative chemotherapy

Pregnancy and patients had concomitant severe liver, heart, and kidney comorbidities.

The control group is hospital-based. The control group consists of healthy adults who attend our hospital outpatient clinic for routine medical check-ups and submit blood samples for routine laboratory workups. Subjects with no markers in their checkups were enrolled in the study as controls with similar proportion to the age and sex of cases. Their ages ranged from 38 to 45 years (Mean $41.08 \pm 2.18$ years). Forty subjects were male and 20 were female in a 2:1 ratio.

All patients and controls were asked to give informed consent before participation in the study. This study followed the guidelines set by our university's local ethical and scientific committees.The procedures followed the ethical principles outlined in the 1964 Helsinki Declaration.

Patients were diagnosed based on complete history, clinical examination, and laboratory investigations, including a complete blood count, an LH 750 (Beckman Coulter), Leishman-stained PB films examination, and bone marrow (BM) aspiration and examination. In addition, flow-cytometric immuno-phenotyping was performed to segregate patients into different $F A B$ subtypes using an EPICS XL Coulter flow cytometer. Also, karyotyping and fluorescence in situ hybridization (FISH) were performed to demonstrate patients' cytogenetic risk categories.Cytogenetic risk groups were determined regarding the $2016 \mathrm{NCCN}$ guidelines [5].

\section{Sample collection}

Peripheral blood and bone marrow samples were collected on ethylene diamine tetra-acetic acid (EDTA) $(1.2 \mathrm{mg} / \mathrm{ml})$ for morphological and immune-phenotypic evaluation and study of the IL4 gene polymorphism. $\mathrm{BM}$ aspirates were collected in sterile, preservativefree, lithium heparin-coated vacutainer tubes for cytogenetic analysis.

\section{Polymerase chain reaction (PCR) technique}

DNA was extracted using a whole blood genomic DNA extraction kit (QIAamp DNA blood mini kit supplied by Qiagen, Hilden, Germany); according to the manufacturer's protocol, all extracts were stored at $-20 \mathrm{C}$. A spectrophotometer was used to measure the absorbance of extracts at $260 \mathrm{~nm}$ and $280 \mathrm{~nm}$ to determine their concentration and purity. PCR was carried out in a volume of $25 \mu \mathrm{L}$ reaction mixture containing genomic DNA, primers, Taq polymerase, $\mathrm{MgCl} 2,10 \times$ reaction buffer, and deoxy-ribonucleoside triphosphate mix using QIAGEN Taq ready to use PCR master mix kit (cat. nos. 201443).

Amplification was performed with primers; the forward primer sequence was $5^{\prime}$ TAG GCT GAA AGG GGG AAA GC $3^{\prime}$ and for the reverse primer was $5^{\prime}$ CTG TTC ACC TCA ACT GCT CC 3'. Amplification was performed in a Biometra T-professional PCR System thermocycler (Analytik Jena AG) using an initial denaturation at $95{ }^{\circ} \mathrm{C}$ for $5 \mathrm{~min}, 30$ cycles of denaturation at $94{ }^{\circ} \mathrm{C}$ for $30 \mathrm{~s}$, annealing at $58^{\circ} \mathrm{C}$ for $45 \mathrm{~s}$, extension at $72{ }^{\circ} \mathrm{C}$ for $1 \mathrm{~min}$ and final extension at $72^{\circ} \mathrm{C}$ for $10 \mathrm{~min}$.

All PCR amplification products were electrophoresed on a $2 \%$ agarose gel stained with ethidium bromide and visualized by UV BioDoc Analyze Darkhood transilluminatior (Biometra, Analytik Jena AG), the PCR product was $183 \mathrm{bp}$ for the P1 allele and $253 \mathrm{bp}$ for the P2 allele.

\section{Treatment regimen}

All patients were induced with standard chemotherapy protocols according to the $2016 \mathrm{NCCN}$ guidelines to receive the standard $3+7$ protocol [6].

Upon achieving complete remission (CR), consolidation to prevent subsequent relapse was given. The type of consolidation conferred depends on the risk of relapse, which is largely dictated by cytogenetics, and the availability of a matching sibling donor (MSD) to undergo allogeneic hematopoietic stem cell transplantation 
(allo-SCT). Patients with a low risk of relapse received high-dose cytarabine for 4 cycles and those lacking a donor received the same consolidation protocol, while patients with MSD and demonstrating intermediate or poor risk cytogenetics were allo-transplanted and received high-dose Cytarabine until they have access to transplantation facility with a maximum of 4 doses [7].

\section{Assessment of response}

On day 28 of the induction cycle, all patients underwent bone marrow examination to determine the status of remission. The follow-up period lasted for up to 24 months with a median of 9 months. Patients were divided into responders attaining $\mathrm{CR}$ and resistant cases according to the European Leukemia Net (ELN 2017) [8]. CR was achieved when the BM examination was normal with less than $5 \%$ blast cells and disappearance of Aeur rods, recovery of absolute neutrophil count $(\mathrm{ANC})>1000 / \mu \mathrm{L}$, and platelets $>100,000 / \mu \mathrm{L}$, the extramedullary disease had resolved and cytogenetic aberrations disappeared. Relapse was defined as the reemergence of leukemic cells in the bone marrow ( $\geq 5 \%$ ) or the peripheral blood or as the appearance of a new extramedullary site of disease in patients with previously reported CR [8].

The European Leukemia Net (ELN) defined primary refractory AML as failure to achieve CR after two courses of intensive induction chemotherapy, excluding patients with aplastic aplasia or death due to an indeterminate cause [9].

Minimal residual disease (MRD) is thus defined as the persistence of leukemic cells after chemotherapy and is responsible for relapse onset. Quantitative MRD frequency assessment can provide important prognostic information after chemotherapy [9].

Overall survival (OS) was determined from the date of diagnosis to the date of death or the last known date to be alive. In contrast, disease-free survival (DFS) was calculated from $\mathrm{CR}$ to the date of relapse or the last follow-up [10].

\section{Statistical analysis}

The data were collected, updated, coded, and fed into the Statistical Package for Social Science (IBM SPSS ${ }^{\mathrm{TM}}$ ) version 20. The normality of data was assessed using Kolmogrov-Smirnov test. Qualitative data are presented as numbers and percentages. Normally distributed data were expressed as mean, standard deviations, and ranges, while skewed distribution data were presented as median with interquartile range (IQR). To compare quantitative variables between two groups, we used Student $t$ test when data were parametric and Mann-Whitney test when skewed. Qualitative data were compared using
Chi-square and Fisher exact when the predicted number was found in any cell less than 5. Kaplan-Meier Analysis using Log Rank test was used to compare median OS and DFS between different groups. Results that reached a level of $P<0.05$ were considered statistically significant.

\section{Results}

The main demographic and clinicopathological characteristics of the studied cohort are presented in Table 1. The polymorphism of the study gene in AML cases and controls is depicted in Table 2 . The genotype distribution of the intron 3 VNTR in IL4 gene was consistent with the Hardy-Weinberg equilibrium both in the control group and in patients $(P>0.05)$.

Table 1 Demographic and clinicopathological characteristics of AML patients

\begin{tabular}{|c|c|}
\hline Variables & AML patient $(n=60)$ \\
\hline Age (years), Mean $\pm S D$ & $43.1 \pm 14.3$ \\
\hline \multicolumn{2}{|l|}{ Sex, $n(\%)$} \\
\hline Male & $42(70)$ \\
\hline Female & $18(30)$ \\
\hline \multicolumn{2}{|l|}{ Extramedullary involvement, $n$ (\%) } \\
\hline Positive & $34(56.7)$ \\
\hline Negative & $26(43.3)$ \\
\hline $\mathrm{TLC}\left(\times 10^{3} / \mu \mathrm{L}\right)$, Median (IQR) & $19.5(5.8-58)$ \\
\hline Hemoglobin (g/dL), mean $\pm S D$ & $7.5 \pm 2.2$ \\
\hline Platelets $\left(\times 10^{3} / \mu \mathrm{L}\right)$, Median (IQR) & $40.5(15-79)$ \\
\hline PB blasts (\%), Median (IQR) & $32(5-63)$ \\
\hline Initial BM blasts (\%), Median (IQR) & $69(50-85)$ \\
\hline \multicolumn{2}{|l|}{ FAB subtype, $n(\%)$} \\
\hline Mo & $3(5.0)$ \\
\hline M1 & $12(20)$ \\
\hline M2 & $32(53.3)$ \\
\hline M4 & $11(18.3)$ \\
\hline M5 & $0(0.0)$ \\
\hline M6 & $0(0.0)$ \\
\hline M7 & $2(3.3)$ \\
\hline \multicolumn{2}{|l|}{ Immunophenotyping, $n$ (\%) } \\
\hline HLA-DR & $53(88.3)$ \\
\hline CD34 & $49(81.7)$ \\
\hline MPOX & $50(83.3)$ \\
\hline \multicolumn{2}{|l|}{ Cytogenetic risk groups, n (\%) } \\
\hline Favorable & $7(11.66)$ \\
\hline Intermediate & $38(63.33)$ \\
\hline Poor & $5(8.33)$ \\
\hline$N A^{*}$ & $10(16.66)$ \\
\hline
\end{tabular}

MPOX myeloperoxidase, NA not applicable, * ${ }^{*}$ ten patients (16.66\%) non-provided data Or failed cytogenetic analysis, Favorable cytogenetic markers: $\mathrm{t}(8 ; 21)$, inv(16); Intermediate cytogenetic markers: normal karyotype, trisomy 8; Unfavorable cytogenetic markers $\mathrm{t}(11 \mathrm{q} 23), \mathrm{t}(9 ; 11)$, monosomy 7 
Table 2 Genotype and allele frequencies of IL4 in patients with $\mathrm{AML}$ and controls

\begin{tabular}{lccc}
\hline Variables & Patients $(\boldsymbol{n = 6 0 )}$ & Control $(\boldsymbol{n}=\mathbf{6 0})$ & P value \\
\hline $\begin{array}{l}\text { Genotype, } n(\%) \\
\text { P1P1 }\end{array}$ & $2(3.3)$ & $42(70.0)$ & $<0.001$ \\
P1P2 & $24(40)$ & $6(10)$ & \\
P2P2 & $34(56.7)$ & $12(20)$ & \\
Alleles, $n$ (\%) & & & $<0.001$ \\
P1 & $28(23.3)$ & $90(75.0)$ & \\
P2 & $92(76.7)$ & $30(25.0)$ & \\
\hline
\end{tabular}

Statistically significant discrepancies were observed between cases and controls in IL-4 intron 3 minisatellite region polymorphism, where the frequencies of P1P2 and P2P2 genotypes were significantly higher in the AML patients than controls $(40 \%, 56.7 \%$ vs $10 \%, 20 \%, P<0.001$, respectively). On the contrary, the homozygous P1P1 genotype was significantly prevalent among the control group, with a frequency of $70 \%$ compared to $3.3 \%$ for the study group $(P<0.001)$ (Table 2$)$.

Moreover, P2 allele demonstrated a significantly higher frequency in the AML cohort versus the controls $(76.7 \%$ vs. $25 \%, P$ value $<0.001)$. Conversely, P1 allele showed a higher frequency among controls with a statistically significant difference (75\% vs. 23. $3 \%, P<0.001)$ (Table 2$)$.

\section{Correlation between intron3 VNTR -IL4 genotypes and clinical and laboratory parameters of AML patients}

To investigate the impact of intron 3 VNTR-IL4 on the clinical and laboratory data of the studied patients, they were stratified based on their genotypes. Clinical and laboratory characteristics were compared between the P2P2 genotype. The combined P1P2 and P1P1 genotypes are presented in Table 3.

This comparison demonstrated that the P2P2 genotype was significantly associated with older age $(P=0.004)$, higher total leucocytic count $(P=0.025)$,

Table 3 Clinical and laboratory data among homozygous carriers of P2 allele versus heterozygous group and non-carriers

\begin{tabular}{|c|c|c|c|}
\hline Variables & $\mathrm{P} 1 \mathrm{P} 1$ and P1P2 $(n=26)$ & $\mathrm{P} 2 \mathrm{P} 2(n=34)$ & $P$ value \\
\hline Age (years), Mean $\pm S D$ & $37.1 \pm 11.50$ & $47.6 \pm 14.70$ & 0.004 \\
\hline Sex, $n(\%)$ & & & 0.909 \\
\hline Male & $18(69.2)$ & $24(70.6)$ & \\
\hline Female & $8(30.8)$ & $10(29.4)$ & \\
\hline Extramedullary involvement, $n(\%)$ & & & 0.700 \\
\hline Positive & $12(46.2)$ & $14(41.2)$ & \\
\hline Negative & $14(53.8)$ & $20(58.8)$ & \\
\hline $\mathrm{TLC}\left(\times 10^{3} / \mu \mathrm{L}\right)$, Median $(\mathrm{IQR})$ & $12.6(4.5-30)$ & $28(15-130)$ & 0.025 \\
\hline Hemoglobin (g/dL), & & & 0.120 \\
\hline Mean $\pm S D$ & $7.82 \pm 2.21$ & $7.2 \pm 2.1$ & \\
\hline Platelets $\left.\left(\times 10^{3} / \mu \mathrm{L}\right), \times 10^{9} / \mathrm{L}\right)$, Median $(\mathrm{IQR})$ & $66(18-141)$ & $19(13-62)$ & 0.010 \\
\hline PB blasts (\%) & & & 0.005 \\
\hline Median (IQR) & $20(2-49)$ & $58(33-69)$ & \\
\hline BM blasts (\%),Median (IQR) & $60(38-80)$ & $80(67-85)$ & 0.023 \\
\hline FAB Subtype, $n(\%)$ & & & 0.973 \\
\hline M0, M1 & $6(23.1 \%)$ & $8(23.5 \%)$ & \\
\hline M2 & $14(53.8 \%)$ & $19(55.9 \%)$ & \\
\hline$M 4 / 5, M 6, M 7$ & $6(23.1 \%)$ & $7(20.6 \%)$ & \\
\hline \multicolumn{4}{|l|}{ Immunophenotyping, n (\%) } \\
\hline HLA-DR & $22(84.6)$ & $31(91.2)$ & 0.432 \\
\hline CD34 & $21(80.8)$ & $28(82.4)$ & 0.874 \\
\hline MPOX & $20(76.9)$ & $30(88.2)$ & 0.244 \\
\hline Cytogenetic risk groups, $n(\%)^{*}$ & & & 0.32 \\
\hline Favorable & $4(19)$ & $3(10)$ & \\
\hline Intermediate and poor & $16(61.53)$ & $27(90)$ & \\
\hline Complete remission & $23(88.55)$ & $22(64.7 \%)$ & 0.035 \\
\hline
\end{tabular}

Bold values indicate significant $p$ value

*Six patients (23\%) from (P1P2 + P1P1) group and four patients (11.76\%) from P2P2 group were excluded due to non -provided data or failed cytogenetic analysis MPOX myeloperoxidase; Favorable cytogenetic markers: $\mathrm{t}(8 ; 21)$, inv(16); Intermediate cytogenetic markers: normal karyotype, trisomy 8; Unfavorable cytogenetic markers $\mathrm{t}(11 \mathrm{q} 23), \mathrm{t}(9 ; 11)$, monosomy 7 
lower platelet count $(P=0.010)$, and a higher count of $\mathrm{PB}$ and $\mathrm{BM}$ blasts than those with P1P2 and P1P1 genotypes ( $P=0.005$ and 0.023 , respectively). However, all the other studied parameters were similar to the studied subgroups (Table 3 ).

\section{Prognostic impact of intron 3 VNTR-IL4 genotypes in AML patients}

When evaluating disease outcomes in our leukemic patients according to their genotypes (P2P2 vs. $\mathrm{P} 1 \mathrm{P} 2+\mathrm{P} 1 \mathrm{P} 1$ genotypes), $\mathrm{CR}$ was found to be a common fate in patients who harbored P1P2 and P1P1 genotypes. Our analysis showed that 23 patients (88.5\%) of this subgroup had achieved CR. In contrast to this observation, among the 34 patients included in the P2P2 subgroup, 22 patients $(64.7 \%)$ showed CR, a $P$ value $=0.035$ (Table3) .

Therefore, it is evident that patients with the P2P2 genotype had a poor disease outcome manifested in their high rate of treatment resistance. However, the combined (P1P2+ P1P1) genotypes showed a favorable impact on disease outcome as most of the patients in this group showed an excellent therapeutic response and attained CR.

\section{Impact of IL4 SNP on the outcome}

After a mean follow-up interval of 12 months, patients with P2P2 had lower OS in comparison with patients with P1P1, P1P2 (OS=38.1\% vs. 44.4\%), 95\% $\mathrm{CI}=3.987-20.013$ vs. $1.876-4.124, P=0.527$ ) (Table 4 , Fig. 1).

Regarding DFS, patients with P2P2 had lower DFS in comparison with patients with P1P1, P1P2 (DFS $=59.10 \%$ vs. $75 \%$ ), 95\% CI $=13.351-21.674$ vs. 14.099-24.901, $P=0.557$ ) (Table 5, Fig. 2).

\section{Correlation between OS, DFS with other variables}

No statistical significance was detected between OS, DFS with age, TLC, HBG, PLT, peripheral blasts, initial

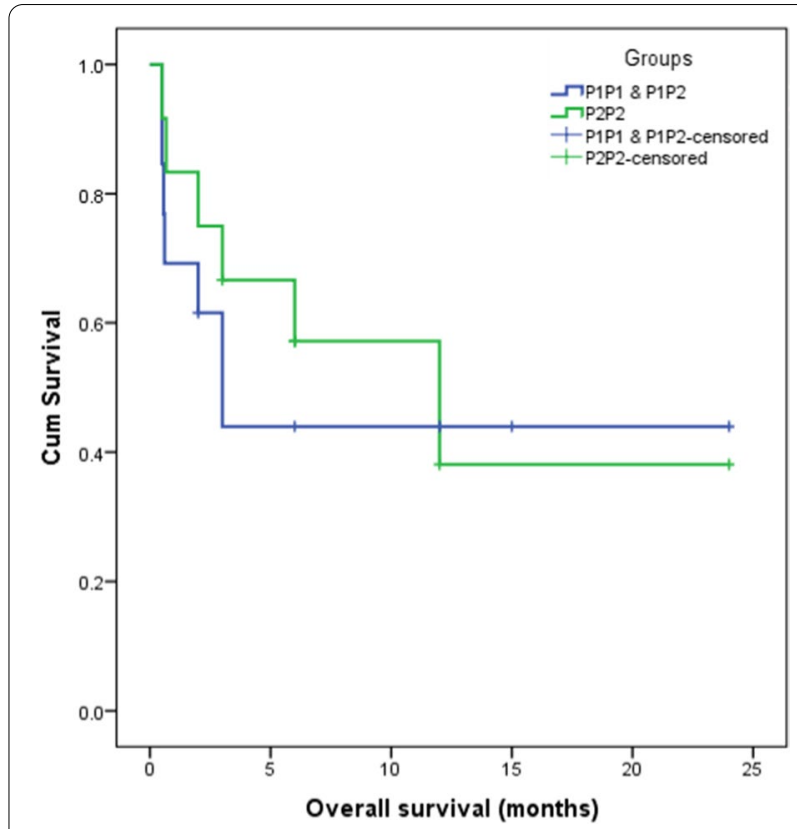

Fig. 1 Kaplan-Meier curves of OS of patients with P2P2 (38.1\%) (green line) and patients with P1P1 and P1P2 (44.40\%) (blue line) after 12 months of follow-up

aspirate, extramedullary involvement, diagnosis, HLADR, CD34, MPO, and PCR products (Tables 6, 7).

\section{Discussion}

Blood cell and hematopoietic stem cell progenitors found in the medullary cavities are susceptible to their environment. Cytokines play a fundamental role in transducing extracellular signals and impulses by binding to their respective receptors on the cell surface [11].

In the context of leukemia, abnormal cytokine levels and aberrant response to them result in perturbed bone marrow niche architecture, which enhances leukemogenesis and disease progression [12]. In AML, these events are well documented [11].

Deregulated cytokine production is attributed to polymorphisms and VNTRs in cytokine genes. These polymorphisms critically influence genetic susceptibility to cancers in several ways, such as affecting

Table 4 Overall survival of the studied AML patients

\begin{tabular}{|c|c|c|c|c|c|c|c|c|c|c|c|}
\hline \multirow[t]{2}{*}{ Groups } & \multirow[t]{2}{*}{ Total N } & \multirow[t]{2}{*}{$\mathrm{N}$ of events } & \multicolumn{2}{|c|}{ OS (months) } & \multicolumn{2}{|l|}{$95 \% \mathrm{Cl}$} & \multicolumn{3}{|c|}{ Survival at (\%) months } & \multicolumn{2}{|c|}{ Log Rank Test } \\
\hline & & & Median & SE & Lower & Upper & 3 months (\%) & 6 months (\%) & 12 months (\%) & $x^{2}$ & $P$ value \\
\hline P1P1 and P1P2 & 26 & 14 & 3 & 0.573 & 1.876 & 4.124 & 61.50 & 44.40 & 44.40 & 0.399 & 0.527 \\
\hline $\mathrm{P} 2 \mathrm{P} 2$ & 24 & 12 & 12 & 4.088 & 3.987 & 20.013 & 66.70 & 57.10 & 38.10 & & \\
\hline
\end{tabular}

OS overall survival, SE standard error, $N$ number 
Table 5 Disease-free survival of the studied AML patients

\begin{tabular}{|c|c|c|c|c|c|c|c|c|c|c|c|}
\hline \multirow[t]{2}{*}{ Groups } & \multirow[t]{2}{*}{ Total N } & \multirow[t]{2}{*}{$\mathrm{N}$ of events } & \multicolumn{2}{|c|}{ PFS (months) } & \multicolumn{2}{|l|}{$95 \% \mathrm{Cl}$} & \multicolumn{3}{|c|}{ PFS at (\%) months } & \multicolumn{2}{|c|}{ Log Rank Test } \\
\hline & & & Median & SE & Lower & Upper & 3 months (\%) & 6 months (\%) & 12 months (\%) & $x^{2}$ & $P$ value \\
\hline $\mathrm{P} 1 \mathrm{P} 1$ and $\mathrm{P} 1 \mathrm{P} 2$ & 18 & 2 & 19.500 & 2.756 & 14.099 & 24.901 & 75.00 & 75.00 & 75.00 & 0.345 & 0.557 \\
\hline P2P2 & 22 & 6 & 17.513 & 2.123 & 13.351 & 21.674 & 90.00 & 78.80 & 59.10 & & \\
\hline
\end{tabular}

DFS disease-free survival, SE standard error, $N$ number

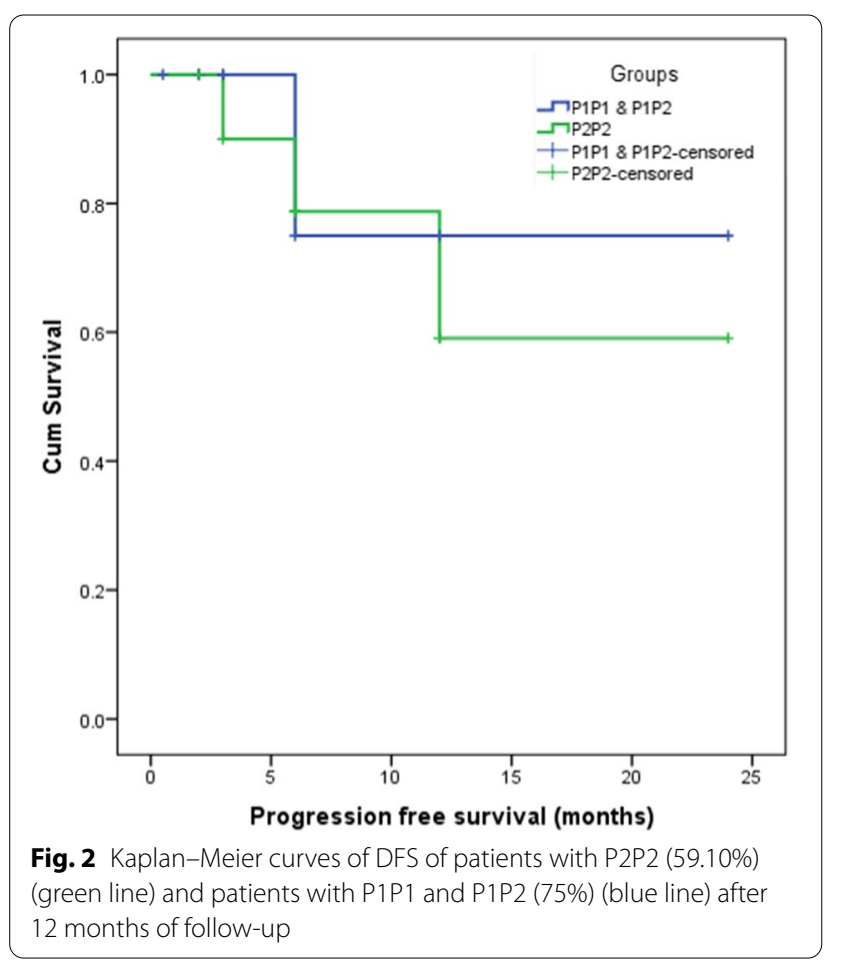

the level and the function of cytokines engaged in immune responses, disrupting nuclear factor binding to targeted genes, and altering apoptosis [13-15].

IL-4 is a crucial cytokine that controls proliferation, differentiation, and apoptosis in hematopoietic and nonhematopoietic cell lineages. Recent investigations have confirmed the essential role of IL4 in the survival of AML cells [16].

The polymorphism of the minisatellite region in the third intron of the IL- 4 gene has attracted increased attention due to its role in changing gene expression. Thus, the amount of IL4 produced [16]. Currently, this IL4 gene polymorphism has been identified as a risk factor affecting susceptibility to carcinogenesis [15]. However, its role as a genetic marker in AML is still undetermined. To date, it is still unknown whether this polymorphism has prognostic value in the stratification of AML risk, as it highlights the factors contributing to the provocation and impairment of blast cells, which are the fundamental basics in AML cell biology with potential treatment outcomes [11].

Therefore, we performed this work to reveal its role and provide a deeper evaluation of its association with clinical and laboratory data and its potential prognostic impact on AML patients.

There are three alleles for IL4 gene VNTR polymorphism, namely, P1 allele, three repeats; P2 allele, two repeats; and P3 allele, four repeats. The P1 allele is the most standard allele, and the P3 allele is the rarest one [17].

In the current study, P1/P2 and P2/P2 genotypes were frequently detected in leukemic patients, and the P2 allele was significantly associated with the disease. These findings are inconsistent with a study by Ahmed et al. [4], in which patients of different kinds of leukemias have been recruited. They observed a higher incidence of allele loss in leukemic patients, and they concluded that P1/P1 and P1/P2 genotypes are collectively associated with leukemogenesis. Moreover, their study confirmed a higher frequency of $\mathrm{P} 1$ allele in leukemic patients. This difference stems from the observed heterogeneity of various types of leukemia in the patients enrolled in their study.

Duan et al. [15] performed a meta-analysis to investigate IL-4 intron 3 VNTR polymorphism and its relationship to cancer risk. They concluded that the P2 allele might be linked to a lower risk of cancer compared to the P1 allele. However, some reservations were raised regarding that meta-analysis. The pooled data were obtained from studies on different cancer types, accounting for heterogeneity. Various types of malignancies might trigger different host responses, and the interplay between environmental factors and the host might also affect susceptibility to different types of cancer [18].

In the present work, patients with the P2P2 genotype had higher leukocytosis, moderate anemia, marked thrombocytopenia, and higher blast percentages compared to heterozygous and non-carriers of the P2 allele. They also had inferior disease outcomes than the other group since they were less responsive to therapy and had a higher incidence of relapse.

It has been evidenced that the IL-4 intron 3 VNTR variant can alter messenger ribonucleic acid splicing 
Table 6 Correlation of overall survival with other variables

\begin{tabular}{|c|c|c|c|c|c|c|c|c|c|c|c|c|c|c|}
\hline & & \multirow[t]{2}{*}{ Total N } & \multirow[t]{2}{*}{$\mathrm{N}$ of events } & \multicolumn{2}{|c|}{ OS (months) } & \multicolumn{2}{|l|}{$95 \% \mathrm{Cl}$} & \multicolumn{4}{|c|}{ Survival at } & \multicolumn{3}{|c|}{ Log Rank test } \\
\hline & & & & Mean & SE & Lower & Upper & $1 \mathrm{m.}(\%)$ & 3 m. (\%) & $6 \mathrm{m.}(\%)$ & $12 \mathrm{~m} .(\%)$ & $\overline{x^{2}}$ & $P$ value & Sig \\
\hline \multicolumn{2}{|l|}{ Overall } & 50 & 26 & 12.346 & 1.565 & 9.279 & 15.412 & 76.0 & 55.3 & 50.6 & 43.4 & - & -- & - \\
\hline \multirow[t]{2}{*}{ Age } & $\leq 45 \mathrm{yrs}$ & 24 & 10 & 14.719 & 2.226 & 10.355 & 19.082 & 87.5 & 56.6 & 56.3 & 56.3 & 1.817 & 0.178 & NS \\
\hline & $>45 \mathrm{yrs}$ & 26 & 16 & 10.379 & 2.082 & 6.298 & 14.46 & 65.4 & 46.2 & 46.2 & 33.0 & & & \\
\hline \multirow[t]{2}{*}{ TLC } & $\mathrm{TLC}<20$ & 27 & 13 & 13.31 & 2.100 & 9.195 & 17.425 & 77.8 & 62.6 & 58.4 & 45.4 & 0.481 & 0.488 & NS \\
\hline & $\mathrm{TLC} \geq 20$ & 23 & 13 & 11.242 & 2.308 & 6.718 & 15.766 & 73.9 & 46.6 & 41.4 & 41.4 & & & \\
\hline \multirow[t]{2}{*}{ HGB } & $<7.5$ & 26 & 11 & 14.399 & 2.169 & 10.148 & 18.649 & 76.9 & 68.8 & 59.6 & 52.2 & 1.587 & 0.208 & NS \\
\hline & $>7.5$ & 24 & 15 & 10.292 & 2.163 & 6.053 & 14.531 & 75.0 & 41.7 & 41.7 & 34.7 & & & \\
\hline \multirow[t]{2}{*}{ PLT } & $<40$ & 27 & 15 & 10.972 & 2.168 & 6.724 & 15.221 & 74.1 & 54.6 & 44.6 & 35.7 & 0.722 & 0.395 & NS \\
\hline & $\geq 40$ & 23 & 11 & 13.638 & 2.265 & 9.199 & 18.077 & 78.3 & 56.5 & 56.5 & 50.2 & & & \\
\hline \multirow[t]{2}{*}{ PB blasts } & $<32$ & 26 & 14 & 12.11 & 2.112 & 7.971 & 16.249 & 73.1 & 61.1 & 52.4 & 39.3 & 0.013 & 0.910 & NS \\
\hline & $>32$ & 24 & 12 & 12.725 & 2.29 & 8.237 & 17.213 & 79.2 & 48.9 & 48.9 & 48.9 & & & \\
\hline \multirow[t]{2}{*}{ Initial aspirate } & $<69$ & 25 & 10 & 14.989 & 2.191 & 10.694 & 19.283 & 80.0 & 67.8 & 63.2 & 55.3 & 2.517 & 0.113 & NS \\
\hline & $>69$ & 25 & 16 & 9.708 & 2.101 & 5.591 & 13.826 & 72.0 & 42.7 & 37.9 & 31.6 & & & \\
\hline \multirow{2}{*}{$\begin{array}{l}\text { Extramedul- } \\
\text { lary involve- } \\
\text { ment }\end{array}$} & Negative & 31 & 17 & 11.876 & 1.942 & 8.07 & 15.681 & 77.4 & 57.0 & 49.4 & 39.6 & 0.124 & 0.725 & NS \\
\hline & Positive & 19 & 9 & 13.474 & 2.55 & 8.476 & 18.471 & 73.7 & 52.6 & 52.6 & 52.6 & & & \\
\hline \multirow[t]{6}{*}{ Diagnosis } & MO & 2 & 2 & 1.5 & 0.5 & 0.52 & 2.48 & 50.0 & 0.0 & 0.0 & 0.0 & 5.682 & 0.338 & NS \\
\hline & M1 & 8 & 3 & 9.7 & 2.397 & 5.002 & 14.398 & 75.0 & 60.0 & 60.0 & 60.0 & & & \\
\hline & M2 & 27 & 15 & 11.601 & 2.112 & 7.461 & 15.74 & 74.1 & 51.0 & 47.1 & 40.3 & & & \\
\hline & M3 & 3 & 1 & 20 & 3.266 & 13.599 & 26.401 & 66.7 & 66.7 & 66.7 & 66.7 & & & \\
\hline & M4 & 8 & 4 & 13.5 & 3.742 & 6.166 & 20.834 & 87.5 & 62.5 & 50.0 & 50.0 & & & \\
\hline & M7 & 2 & 1 & 3.5 & 1.768 & 0.035 & 6.965 & 50.0 & 50.0 & 50.0 & 50.0 & & & \\
\hline \multirow[t]{2}{*}{ HLA-DR } & Negative & 8 & 2 & 19.025 & 3.054 & 13.038 & 25.012 & 87.5 & 87.5 & 87.5 & 70.0 & 2.942 & 0.086 & NS \\
\hline & Positive & 42 & 24 & 11.085 & 1.702 & 7.75 & 14.42 & 73.8 & 48.9 & 43.4 & 38.6 & & & \\
\hline \multirow[t]{2}{*}{ CD34 } & Negative & 11 & 4 & 16.073 & 3.138 & 9.922 & 22.224 & 81.8 & 72.7 & 72.7 & 58.2 & 1.414 & 0.234 & NS \\
\hline & Positive & 39 & 22 & 11.263 & 1.764 & 7.806 & 14.721 & 74.4 & 50.0 & 44.1 & 39.2 & & & \\
\hline \multirow[t]{2}{*}{ MPOX } & Negative & 8 & 4 & 12.875 & 3.939 & 5.155 & 20.595 & 75.0 & 50.0 & 50.0 & 50.0 & 0.000 & 0.988 & NS \\
\hline & Positive & 42 & 22 & 12.285 & 1.698 & 8.956 & 15.613 & 76.2 & 56.3 & 50.9 & 42.4 & & & \\
\hline \multirow[t]{3}{*}{ PCR product } & P1P1 & 1 & 0 & - & - & - & - & 100.0 & 100.0 & 100.0 & 100.0 & 1.561 & 0.458 & NS \\
\hline & P2P2 & 29 & 14 & 13.285 & 2.039 & 9.289 & 17.282 & 72.4 & 61.9 & 58.0 & 46.4 & & & \\
\hline & P1P2 & 20 & 12 & 10.438 & 2.421 & 5.693 & 15.184 & 80.0 & 43.1 & 36.9 & 36.9 & & & \\
\hline
\end{tabular}

resulting in different splice variants. There is strong evidence that IL4 VNTR polymorphism may alter IL-4 synthesis, with the P1 allele boosting IL-4 expression compared to the P2 allele [19].

Together with ours, this finding raises questions regarding the mechanism by which IL4 affects leukemic cells growth and survival and whether a P2P2 genotype with lower IL4 expression causes more malignant clone and resistant disease.

According to a recent study, IL4 is an inhibitor of AML cells that appears as the first hit to leukemic cells because it showed the most selective suppression of their growth while retaining normal bone marrow cells. The authors of this study referred to its antileukemic effect to STAT6 being a downstream mediator of
IL4 signaling and a crucial signaling pathway in macrophage function and activation. In a STAT 6-dependent manner, IL4 selectively triggers programmed cell death of AML cells [20].

Indeed, our patients with the P2P2 genotype and lower IL4 expression had higher blast percentages, increased therapy resistance, a higher incidence of relapse, shorter OS, and a worse disease outcome when compared to the heterozygous and non-carrier of the P2 allele.

Several reports indicate that IL-4 is the central cytokine of T-helper 2 cells that enhances the differentiation and function of CD4 and CD8-T cells [21]. Moreover, some tumors contained IL4 in their microenvironment, primarily expressed by tumor-infiltrating leucocytes [22, 23]. 
Table 7 Correlation of progression free survival with other variables

\begin{tabular}{|c|c|c|c|c|c|c|c|c|c|c|c|c|c|c|}
\hline & & \multirow[t]{2}{*}{ Total N } & \multirow[t]{2}{*}{$\mathrm{N}$ of events } & \multicolumn{2}{|c|}{$\begin{array}{l}\text { PFS } \\
\text { (months) }\end{array}$} & \multicolumn{2}{|l|}{$95 \% \mathrm{Cl}$} & \multicolumn{4}{|c|}{ Survival at } & \multicolumn{3}{|c|}{ Log Rank test } \\
\hline & & & & Mean & SE & Lower & Upper & $1 \mathrm{~m} .(\%)$ & $3 \mathrm{m.}(\%)$ & $6 \mathrm{~m} .(\%)$ & $12 \mathrm{~m} .(\%)$ & $\overline{x^{2}}$ & $P$ value & Sig \\
\hline \multicolumn{2}{|l|}{ Overall } & 40 & 8 & 18.31 & 1.68 & 15.03 & 21.60 & 100.0 & 93.8 & 78.1 & 65.1 & - & - & - \\
\hline \multirow[t]{2}{*}{ Age } & $\leq 45 \mathrm{yrs}$ & 22 & 3 & 20.14 & 1.97 & 16.27 & 24.01 & 100.0 & 100.0 & 78.6 & 78.6 & 0.997 & 0.318 & NS \\
\hline & $>45 \mathrm{yrs}$ & 18 & 5 & 16.65 & 2.51 & 11.72 & 21.58 & 100.0 & 87.5 & 78.8 & 52.5 & & & \\
\hline \multirow[t]{2}{*}{ Sex } & Females & 24 & 3 & 10.41 & 0.83 & 8.79 & 12.03 & 100.0 & 88.2 & 79.4 & 79.4 & 0.090 & 0.764 & NS \\
\hline & Males & 16 & 5 & 17.79 & 2.19 & 13.50 & 22.08 & 100.0 & 100.0 & 78.6 & 58.9 & & & \\
\hline \multirow[t]{2}{*}{ TLC } & $\mathrm{TLC}<20$ & 21 & 4 & 18.49 & 2.22 & 14.13 & 22.85 & 100.0 & 100.0 & 85.7 & 61.2 & 0.179 & 0.672 & NS \\
\hline & $T L C \geq 20$ & 19 & 4 & 18.08 & 2.50 & 13.19 & 22.97 & 100.0 & 86.7 & 69.3 & 69.3 & & & \\
\hline \multirow[t]{2}{*}{ HGB } & $<7.5$ & 21 & 4 & 18.57 & 2.27 & 14.13 & 23.01 & 100.0 & 100.0 & 78.6 & 65.5 & 0.062 & 0.803 & NS \\
\hline & $>7.5$ & 19 & 4 & 18.23 & 2.43 & 13.46 & 22.99 & 100.0 & 87.5 & 78.8 & 65.6 & & & \\
\hline \multirow[t]{2}{*}{ PLT } & $<40$ & 21 & 4 & 17.71 & 2.57 & 12.68 & 22.74 & 100.0 & 93.3 & 76.4 & 61.1 & 0.088 & 0.767 & NS \\
\hline & $\geq 40$ & 19 & 4 & 18.79 & 2.21 & 14.47 & 23.12 & 100.0 & 94.1 & 79.6 & 68.3 & & & \\
\hline \multirow[t]{2}{*}{ PB blasts } & $<32$ & 19 & 5 & 16.69 & 2.47 & 11.85 & 21.53 & 100.0 & 93.3 & 77.8 & 51.9 & 0.625 & 0.429 & NS \\
\hline & $>32$ & 21 & 3 & 19.94 & 2.09 & 15.84 & 24.04 & 100.0 & 94.1 & 78.4 & 78.4 & & & \\
\hline \multirow[t]{2}{*}{ Initial aspirate } & $<69$ & 20 & 3 & 19.20 & 2.40 & 14.51 & 23.89 & 100.0 & 100.0 & 84.6 & 67.7 & 0.492 & 0.483 & NS \\
\hline & $>69$ & 20 & 5 & 17.40 & 2.39 & 12.71 & 22.10 & 100.0 & 88.2 & 72.2 & 61.9 & & & \\
\hline \multirow{2}{*}{$\begin{array}{l}\text { Extramedul- } \\
\text { lary involve- } \\
\text { ment }\end{array}$} & Negative & 25 & 7 & 16.78 & 2.10 & 12.67 & 20.88 & 100.0 & 95.0 & 71.2 & 55.4 & 1.599 & 0.206 & NS \\
\hline & Positive & 15 & 1 & 22.25 & 1.68 & 18.97 & 25.53 & 100.0 & 91.7 & 91.7 & 91.7 & & & \\
\hline \multirow[t]{6}{*}{ Diagnosis } & MO & 1 & 0 & - & - & - & - & 100.0 & 100.0 & 100.0 & 100.0 & 0.139 & 0.933 & NS \\
\hline & M1 & 7 & 0 & - & - & - & - & 100.0 & 100.0 & 100.0 & 100.0 & & & \\
\hline & M2 & 20 & 5 & 17.59 & 2.35 & 12.99 & 22.20 & 100.0 & 88.2 & 74.7 & 62.2 & & & \\
\hline & M3 & 3 & 1 & 20.00 & 3.27 & 13.60 & 26.40 & 100.0 & 100.0 & 100.0 & 66.7 & & & \\
\hline & M4 & 8 & 2 & 16.80 & 3.94 & 9.07 & 24.53 & 100.0 & 100.0 & 60.0 & 60.0 & & & \\
\hline & M7 & 1 & 0 & - & - & - & - & 100.0 & 100.0 & 100.0 & 100.0 & & & \\
\hline \multirow[t]{2}{*}{ HLA-DR } & Negative & 7 & 1 & 21.00 & 2.60 & 15.91 & 26.09 & 100.0 & 100.0 & 100.0 & 75.0 & 0.602 & 0.438 & NS \\
\hline & Positive & 33 & 7 & 17.79 & 1.94 & 13.99 & 21.60 & 100.0 & 92.3 & 72.9 & 63.8 & & & \\
\hline \multirow[t]{2}{*}{ CD34 } & Negative & 10 & 1 & 21.60 & 2.15 & 17.39 & 25.81 & 100.0 & 100.0 & 100.0 & 80.0 & 1.477 & 0.224 & NS \\
\hline & Positive & 30 & 7 & 17.17 & 2.09 & 13.08 & 21.26 & 100.0 & 91.7 & 70.1 & 60.1 & & & \\
\hline \multirow[t]{3}{*}{ PCR product } & P1P1 & 1 & 0 & - & - & - & - & 100.0 & 100.0 & 100.0 & 100.0 & 0.482 & 0.786 & NS \\
\hline & P2P2 & 22 & 5 & 18.06 & 2.15 & 13.85 & 22.27 & 100.0 & 94.1 & 81.6 & 61.2 & & & \\
\hline & P1P2 & 17 & 3 & 18.32 & 2.80 & 12.83 & 23.81 & 100.0 & 92.9 & 69.6 & 69.6 & & & \\
\hline
\end{tabular}

In support of these reports, IL-4 expressed by tumors or $\mathrm{T}$ cells had been observed to improve tumor elimination with innate immunity acting in synergy with CD8 + T cells to decrease tumor load [24].

Similarly, Gitlitz et al. [25] concluded that IL-4 with granulocyte macrophage-colony stimulating factor (GM-CSF) boosts the quantity and performance of antigen-presenting cells in cancer patients. Moreover, the anti-tumor activity of IL 4 has been shown in experiments on various cancers such as colon, breast, and renal carcinoma $[26,27]$.

In contrast to the findings above, other studies indicated that IL-4 produced by the tumor hinders apoptosis, causing the immortalization of malignant cells [16]. It has been reported that IL-4 induces the development and metastasis of head and neck squamous carcinoma [28-30].

Based on previous findings, it can be confirmed that IL-4 is a potent tumor immune modulator with both tumor-promoting and tumor-suppressing features. How IL-4 will interact either way is primarily determined by the type of tumor-clearing effector cell (adaptive/innate) and the kind of tumor cell studied. That is why a single molecule can adversely influence different tumor models and how innate and adaptive immunity will respond [24].

Since IL4 has contradictory effects on tumor immunity, gene sequence variations can still affect gene expression and function. It will significantly benefit investigating the association between IL-4 polymorphism variants and the risk of several human cancers. In addition to determining 
the molecular mechanisms underlying cell responses to IL-4 in various cancer types, it may provide valuable information for designing new risk stratification models and novel treatments for cancer patients.

\section{Conclusions}

The IL4 intron 3 VNTR polymorphism could be considered a novel genetic marker in AML predicting poor disease outcomes. Incorporating this molecular predictor into future AML therapeutic protocols improves patients' counseling and risk stratification. Moreover, it could pave the way for advancing biological therapies that use the IL- 4 effect on AML cells to improve overall disease outcomes.

Further studies on a larger scale of patients with more extended follow-up periods are needed to validate our observations and confirm the effect of this polymorphism on the clinical outcome.

\begin{abstract}
Abbreviations
AML: Acute myeloid leukemia; IL-4: Interleukin-4; VNTR: Variable number of tandem repeat; PCR: Polymerase chain reaction; Th2: T-helper 2; BM: Bone marrow; FISH: Fluorescence in situ hybridization; EDTA: Ethylene diamine tetraacetic acid; CR: Complete remission; MSD: Matched sibling donor; OS: Overall survival; DFS: Disease-free survival; allo-SCT: Allogeneic hematopoietic stem cell transplantation; GM-CSF: Granulocyte macrophage-colony stimulating factor.
\end{abstract}

\section{Acknowledgements}

Not applicable.

\section{Authors' contributions}

NA contributed to the design and implementation of the research, to the analysis of the results and to the writing of the manuscript. MR worked out almost all of the technical details, supervised the work and revised the final manuscript. AM collected the patients' data, contributed to the interpretation of the results regarding clinical outcome and therapeutic response, shared in writing and revising the manuscript. HS collected the patients' data, contributed to the interpretation of the results regarding clinical outcome and therapeutic response, shared in writing and revising the manuscript. All authors read and approved the final manuscript.

\section{Funding}

None.

\section{Availability of data and materials}

All data generated or analyzed during this study are included in this published article.

\section{Declarations}

\section{Ethics approval and consent to participate}

The procedures applied in this study were approved by the Ethical Committee of Human Experimentation of Ain Shams University and are in accordance with the Helsinki Declaration of 1975. FWA 000017585. All patients and controls were asked to give an informed written consent before participation in the study.

\section{Consent for publication}

Not applicable.

\section{Competing interests}

The authors declare that they have no conflict of interests.

\section{Author details}

${ }^{1}$ Clinical Pathology Department, Clinical Hematology and Oncology Unit, Faculty of Medicine, Ain Shams University, Cairo, Egypt. ${ }^{2}$ Clinical Hematology and Bone Marrow Transplantation Unit, Department of Internal Medicine, Faculty of Medicine, Ain Shams University, Cairo, Egypt.

Received: 21 May 2021 Accepted: 29 January 2022

Published online: 04 March 2022

\section{References}

1. Goldstein R, Hanley C, Morris J, Cahill D, Chandra A et al (2011) Clinical investigation of the role of interleukin- 4 and interleukin-13 in the evolution of prostate cancer. Cancers (Basel) 3:4281-4293

2. Burnett $A$, Wetzler $M$, Lowenberg B (2011) Therapeutic advances in acute myeloid leukemia. J Clin Oncol 29:487-494

3. Mittal RD, Manchanda PK (2007) Association of interleukin (IL)-4 intron-3 and IL-6 - $174 \mathrm{G} / \mathrm{C}$ gene polymorphism with susceptibility to end-stage renal disease. Immunogenetics 59:159-165

4. Ahmed A, Abdelgadir R, Muddathir AR, Elshibli EM, Fadl-Elmula IM et al (2016) Interleukin-4 intron 3 VNTR polymorphism gene in leukemic patients. Blood Disord Transfus 7:3

5. National Comprehensive Cancer Network. Acute myeloid leukemia. National Comprehensive Cancer Network Clinical practice Guidelines in oncology V2. 2016

6. Sanz MA, Montesinos P, Rayo'n C, Holowiecka A, de la Serna J et al (2010) Risk-adapted treatment of acute promyelocytic leukemia based on all-trans retinoic acid and anthracycline with addition of cytarabine in consolidation therapy for high-risk patients: further improvements in treatment outcome. Blood 115:5137-5146

7. Rahman MH, Khan MA, Islam MS, Afrose S, Ara T et al (2012) High dose cytosine arabinoside in the consolidation of adult acute myeloid leukemia. Mymensingh Med J 21:213-219

8. Bloomfield C, Estey E, Pleyer L, Schuh A, Eytan M, Martin S, Andrew T (2018) Time to repeal and replace response criteria for acute myeloid leukemia. Blood Rev 32(5):416-425

9. Dohner H, Estey E, Grimwade D et al (2017) Diagnosis and management of AML in adults: 2017 ELN recommendations from an international expert panel. Blood 129:424-447

10. Prebet T, Bertoli S, Thomas X, Tavernier E, Braun T et al (2014) Core-binding factor acute myeloid leukemia in first relapse: a retrospective study from the French AML Intergroup. Blood 124:1312-1319

11. Kupsa T, Horacek JM, Jebavy $L$ (2012) The role of cytokines in acute myeloid leukemia: a systematic review. Biomed Pap Med Fac Univ Palacky Olomouc Czech Repub 156(4):291-301

12. Mirantes C, Passegue E, Pietras EM (2014) Pro-inflammatory cytokines: emerging players regulating HSC function in normal and diseased hematopoiesis. Exp Cell Res 329:248-254

13. Imyanitov EN (2009) Gene polymorphisms, apoptotic capacity and cancer risk. Hum Genet 125:239-246

14. Jin P, Panelli MC, Marincola FM, Wang E (2004) cytokine polymorphism and its possible impact on cancer. Immunol Res 30(2):181-190

15. Duan Y, Pan C, Shi J, Chen H, Zhang S et al (2014) Association between interleukin-4 gene intron 3VNTR polymorphism and cancer risk. Cancer Cell Int 14:131

16. Zamorano J, Rivas M, Pérez GM (2003) Interleukin-4: a multifunctional cytokine. Immunologia 22(2):215-224

17. Elghoroury EA, Fadel FI, Farouk H, Manal FE, Solaf K et al (2018) Association of variable number tandem repeats polymorphism in the IL-4 gene with end-stage renal disease in children. Egypt J Med Hum Genet 19:191-195

18. Salimi S, Khorasani M, Namazi L, Moossavi M, Naghavi A et al (2014) Association between interleukin 4 gene seventy-base-pair variable number of tandem repeats polymorphism and uterine leiomyoma. Gene Cell Tissue 1(2):e19462

19. Nakashima H, Miyake K, Inoue Y, Shimizu S, Akahoshi M et al (2002) Association between IL-4 genotype and IL-4 production in the Japanese population. Genes Immun 3(2):107-109 
20. Peña-Martínez PE, Eriksson M, Ramakrishnan R, Chapellier M, Hogberg C et al (2018) Interleukin 4 induces apoptosis of acute myeloid leukemia cells in a Stat6-dependent manner. Leukemia 32:588-596

21. Northrop JK, Thomas RM, Wells AD, Shen H (2006) Epigenetic remodeling of the IL-2 and IFN-gamma loci in memory CD8 T cells is influenced by CD4 T cells. J Immunol 177(2):1062-1069. https://doi.org/10.4049/jimmu nol.177.2.1062

22. Fasano S, Mauro D, Macaluso F, Xiao F, Zhao Y, Lu L, Guggino G, Ciccia F (2020) Pathogenesis of primary Sjögren's syndrome beyond B lymphocytes. Clin Exp Rheumatol 126:315-323

23. Conticello C, Pedini F, Zeuner A, Patti M, Zerilli M et al (2004) IL-4 protects tumor cells from anti-CD95 and chemotherapeutic agents via upregulation of antiapoptotic proteins. J Immunol 172:5467-5477

24. Olver S, Apte S, Baz A, Kienzle N (2007) The duplicitous effects of interleukin 4 on tumour immunity: how can the same cytokine improve or impair control of tumour growth? J Compil 69:293-298

25. Gitlitz BJ, Figlin RA, Kiertscher SM, Moldawer N, Rosen F et al (2003) Phase I trial of granulocyte macrophage-colony stimulating factor and interleukin-4 as a combined immunotherapy for patients with cancer. J Immunother 26:171-178

26. Nagai S, Toi M (2000) Interleukin-4 and breast cancer. Breast Cancer 7(3):181-186

27. Yu SJ, Kim HS, Cho SW, Sohn J (2004) IL-4 inhibits proliferation of renal carcinoma cells by increasing the expression of p21WAF1 and IRF-1. Exp Mol Med 36(4):372-379

28. Vairaktaris E, Yannopoulos A, Vassiliou S, Yapijakis C, Friedrich W, Patsouris E et al (2007) Strong association of interleukin-4 ( -590 C/T) polymorphism with increased risk for oral squamous cell carcinoma in Europeans. Oral Maxillofac Pathol 104(6):796-802. https://doi.org/10.1016/j.tripleo. 2006.12 .029

29. Manchanda P, Sharma SC, Das SN (2006) Differential regulation of IL-2 and IL-4 in patients with tobacco-related oral squamous cell carcinoma. Oral Dis 12(5):455-462

30. Agarwal A, Rani M, Saha GK, Valarmathi TM, Bahadur S et al (2003) Disregulated expression of the Th2 cytokine gene in patients with intraoral squamous cell carcinoma. Immunol Investig 32(1-2):17-30

\section{Publisher's Note}

Springer Nature remains neutral with regard to jurisdictional claims in published maps and institutional affiliations.

\section{Submit your manuscript to a SpringerOpen ${ }^{\circ}$ journal and benefit from:}

- Convenient online submission

- Rigorous peer review

- Open access: articles freely available online

- High visibility within the field

- Retaining the copyright to your article 